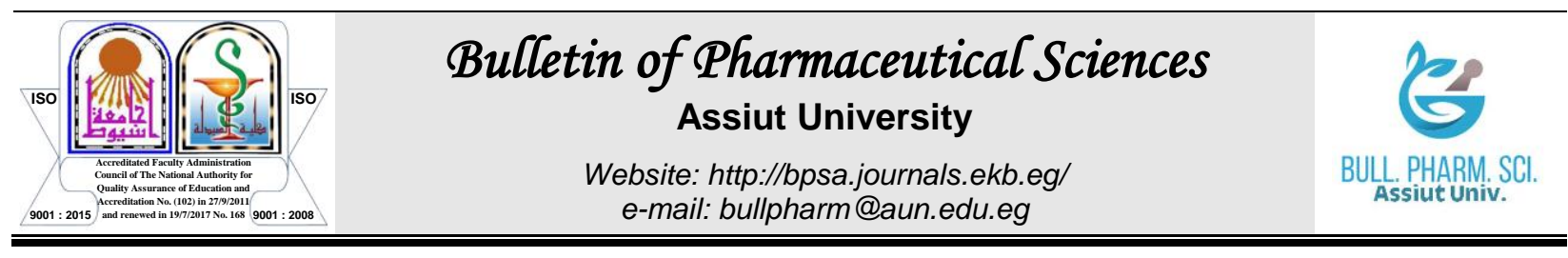

\title{
THE POTENTIAL DRUG-DRUG INTERACTION BETWEEN WARFARIN AND GLIBENCLAMIDE IN DIABETIC AND HYPERCOAGULABLE RATS MODEL
}

\author{
Safaa Y. Salim*, Mohammed S. Molla and Mahmoud H. Abdel-Rahim \\ Pharmacology Department, Faculty of Medicine, Assiut University, Egypt
}

\begin{abstract}
Diabetic patients are vulnerable to many vascular events. So, diabetic patients treated with oral antidiabetic glibenclamide, may be also treated with oral anticoagulant warfarin, for prophylaxis and treatment of atherothrombotic events. Aim of this study: was to evaluate the possible drug-drug interaction between warfarin and glibenclamide in diabetic and hypercoagulable rats. Material and methods: Fifty adult male albino rats (230-390 gm) were enrolled and subgrouped into; I: control group; II: diabetic and hypercoagulable group; III: as group II but treated with warfarin $(0.07 \mathrm{mg} / \mathrm{kg})$ orally for 5 consecutive days; Group IV: as group III but treated with glibenclamide $(0.6 \mathrm{mg} / \mathrm{kg})$ orally for 5 consecutive days and group V: as group IV but treated with both warfarin and glibenclamide. The following parameters were then assessed; prothrombin time, activated partial thromboplastin time, clotting time, bleeding time, serum glucose level and glycosylated hemoglobin. Results: The results showed that, PT, $a P T T, C T, B T$ were significantly $(p<0.001)$ prolonged while the serum glucose level was significantly $(p<0.001)$ decreased and HbAlc was significantly $(p<0.01)$ decreased when warfarin and glibenclamide were administered together more than when they were given alone. Conclusion: A drug-drug interaction had occurred when warfarin and glibenclamide were coadministered.
\end{abstract}

\section{INTRODUCTION}

Global diabetes prevalence is expected to be 9.3 percent (463 million people) in 2019 , increasing to 10.2 percent (578 million) by 2030 and 10.9 percent (700 million) by 2045 . According to the International Diabetes Federation Atlas, it is projected that 15.2 percent of adults in Egypt have diabetes ${ }^{1}$.

The majority of diabetes-related morbidity and death is due to the disease's detrimental influence on macrovascular and microvascular disorders. T2DM has microvascular consequences such as retinopathy, neuropathy, and nephropathy, as well as macrovascular complications such as ischemic heart disease, cerebrovascular disease, and peripheral vascular disorders. Macrovascular disease develops as a result of underlying obstructive atherosclerotic changes of major arteries which cause functional and structural abnormalities of blood vessels ${ }^{2}$. Of the most commonly used in treatment of type DM is glibenclamide that is an insulin secretagogues ${ }^{3}$. Warfarin has been used as anticoagulant agent where it inhibits vitamin $\mathrm{K}$ epoxide reductase with subsequent no synthesis of vitamin $\mathrm{K}$ dependant factors by the liver ${ }^{4}$.

Diabetes is typically managed by treating concomitant diseases such as thrombosis 5 . Warfarin is one of the medicines that can be co-administered with glibenclamide in patients with diabetes mellitus for treatment of thrombosis and thromboprophylaxis with the possibility of drug-drug interaction between them ${ }^{6}$. The present study aimed to evaluate the possible drug-drug interactions between warfarin and glibenclamide in diabetic and hypercoagulable rats. 


\section{MATERIALS AND METHODS}

\section{Animals}

Fifty adult male albino rats weighing 230390 grams were obtained from the animal house. They were housed in stainless-steel cages (five rats in each cage). The animals were housed with ideal conditions of temperature $\left(22 \pm 2^{\circ} \mathrm{C}\right)$ and humidity $(55 \pm 5 \%)$ with 12-light/12-dark cycle. and free access to dry food pellets and tape water. They were kept for one week to adapt the laboratory conditions before starting the experiment. Animal handling and rights were maintained on accordance with the Ethical Committee guidelines of the Faculty of Medicine, Assiut University.

\section{Chemicals}

Warfarin and Glibenclamide were obtained from (AK Scientific, Inc., Union City, U.S.A.), Ellagic acid hydrate (Alfa Aesar, Karlsruhe, Germany), Alloxan monohydrate (Alpha Chemika, Mumbai, India), PT and aPTT assay reagents (Biomed Diagnostics, Hannover, Germany), Glucose assay kit (Spinreact, Girona, Spain) and HbA1c assay kit (Teco Diagnostics, Anaheim, U.S.A.).

\section{Induction of DM}

Single intraperitoneal (IP) injection of alloxan monohydrate in normal saline at a dose $120 \mathrm{mg} / \mathrm{kg}$ after overnight fasting was used to induce $\mathrm{DM}^{7}$. To avoid hypoglycaemia, the rats were given $5-10 \mathrm{ml}$ of a $20 \%$ glucose solution orally after 6 hours and kept 5\% glucose solution for the next $24 \mathrm{hrs}$. Then, they were stabilized in their cages for 7 days ${ }^{8}$.

Assessment the glucose level at $7^{\text {th }}$ day, selected rats should have level above 250 $\mathrm{mg} / \mathrm{dl}^{7}$ and started the treatment by warfarin, glibenclamide or both for 5 consecutive days.

\section{Hypercoagulable state induction}

This was performed by IP ellagic acid hydrate at a dose $10.5 \mathrm{mg} / \mathrm{kg}$ after $2 \mathrm{hrs}$ from the last dose of treatment and five minutes before collection of the blood samples at the $5^{\text {th }}$ day'.

\section{Preliminary experiment to adjust the dose of warfarin in rats}

Three groups of animals (3 rats in each group) were used to select the dose of warfarin that would result in a PT of $1.5-2$ folds ${ }^{10}$ of the control value ( 25 seconds).

- Group A: According to Zaghloul et al., ${ }^{10}$, the rats were received warfarin at a dose $0.1 \mathrm{mg} / \mathrm{kg}$ orally along five days. The animals showed hemorrhage in the form of ecchymosis, epistaxis, bleeding from mouth then died on the $4^{\text {th }}$ day of treatment. This dose was considered as a toxic dose.

- Group B: The rats were received warfarin $0.05 \mathrm{mg} / \mathrm{kg}$ orally for 5 consecutive days. On the $5^{\text {th }}$ day of treatment, PT and concentration was measured after $2 \mathrm{hrs}$. from the last dose of warfarin. It was $32.33 \pm 1.45$ seconds.

- Group C: The rats were received warfarin at a dose $0.07 \mathrm{mg} / \mathrm{kg}$ orally for 5 consecutive days. On the $5^{\text {th }}$ day of treatment, PT and concentration was measured after 2 hours from the last dose of warfarin. It was $40.00 \pm 1.15$ seconds. From the preliminary experiment, 0.07 $\mathrm{mg} / \mathrm{kg}$ / day was suitable to produce a PT and concentration range of 1.5-2 folds of control value and considered as a submaximal dose.

\section{Animal groups and treatments}

The rats were divided into 5 groups (10 rats in each group) as follow: Group I: (control group); received distilled water followed by $0.05 \%$ carboxymethylcellulose (CMC) solution. Diabetic hypercoagulable rats were divided into four groups; Group II: diabetic and hypercoagulable rats were received distilled water followed by $0.05 \%$ CMC solution; Group III: diabetic and hypercoagulable rats treated with warfarin at a dose $0.07 \mathrm{mg} / \mathrm{kg}$; Group IV: diabetic and hypercoagulable rats treated with glibenclamide at a dose $0.6 \mathrm{mg} / \mathrm{kg}^{11 \& 12}$; and Group V: diabetic and hypercoagulable rats treated with warfarin and glibenclamide. All drugs were given orally through gastric tube for 5 consecutive days.

\section{Blood sample collection}

After $5 \mathrm{~min}$. from ellagic acid administration, the blood samples were 
collected from the retro-orbital sinus under general anesthesia by a capillary tube inserted in the medial canthus medial to the eye globe from each animal after overnight fast ${ }^{13}$. Blood was withdrawn into 3 clean test tubes as follow: First tube (containing $0.1 \mathrm{ml}$ of trisodium citrate $3.8 \%$ ): About $0.9 \mathrm{ml}$ of blood was withdrawn into it (in a ratio of 9 parts blood: 1part trisodium citrate). Then, it was centrifuged for 10 minutes at $3000 \mathrm{rpm}$ to separate plasma for determination of PT and aPTT. Second tube [containing ethylene diamine tetra acetic acid (EDTA)]: About 0.5 $\mathrm{ml}$ of blood was withdrawn into it for determination of $\mathrm{HbA} 1 \mathrm{c}$ concentration. Third tube: About $0.5 \mathrm{ml}$ of blood was withdrawn into it and centrifuged for 10 minutes at 3000 $\mathrm{rpm}$ to separate serum for determination of glucose level.

\section{Assessment of coagulation parameters}

Prothrombin time and activated partial thromboplastin time were determined by using commercial kits. The tests were performed according to the manufacturer's instructions. Bleeding time was determined by making a small cut in the middle of the tail with a scalpel and the stopwatch was started as soon as bleeding started. The cut was dabbed with filter paper every 15 seconds until the paper no longer stained red with blood. Bleeding time was then taken as the time when the blood stopped flowing from the cut ${ }^{14 \& 15}$.

Clotting time was determined by taking a drop of blood from the tail of each rat then placed on a clean glass slide and a stopwatch was started at the same time. A pin was passed across the drop of blood once every 15 seconds. As soon as threads of fibrin were noticed, the stopwatch was stopped, and the time recorded is the $\mathrm{CT}^{16}$.

\section{Measurement of serum glucose level}

Serum glucose level was measured by using the commercial assay kit according to the manufacturer's instructions.

\section{Measurement of HbA1c level}

HbA1c level was determined by using a glycosylated hemoglobin assay kit. The test was performed according to the manufacturer's instructions.

\section{Statistical analysis of data}

The data were presented as means \pm standard errors (SE) and analyzed by one-way analysis of variance (ANOVA). For the comparison of statistical significance between two groups, Student's unpaired t-test was used. A P-value of $<0.05$ was adopted as statistically significant. Data analysis was performed by using Graph Pad Prism 5.01 (Graph Pad software Inc., San Diego, USA).

\section{RESUTS AND DISCUSSION}

\section{Results \\ Effect on coagulation parameters}

As shown in figures $1,2,3$ and 4 , PT, aPTT, BT and CT were significantly ( $\mathrm{p}<$ 0.001) shortened in diabetic and hypercoagulable rats (group II) in comparison with control rats (group I). In diabetic and hypercoagulable rats treated with warfarin 0.07 $\mathrm{mg} / \mathrm{kg}$ orally for 5 consecutive days (group III), PT, aPTT, BT and CT were significantly ( $<<$ 0.001 ) prolonged than non-treated diabetic and hypercoagulable rats (group II).

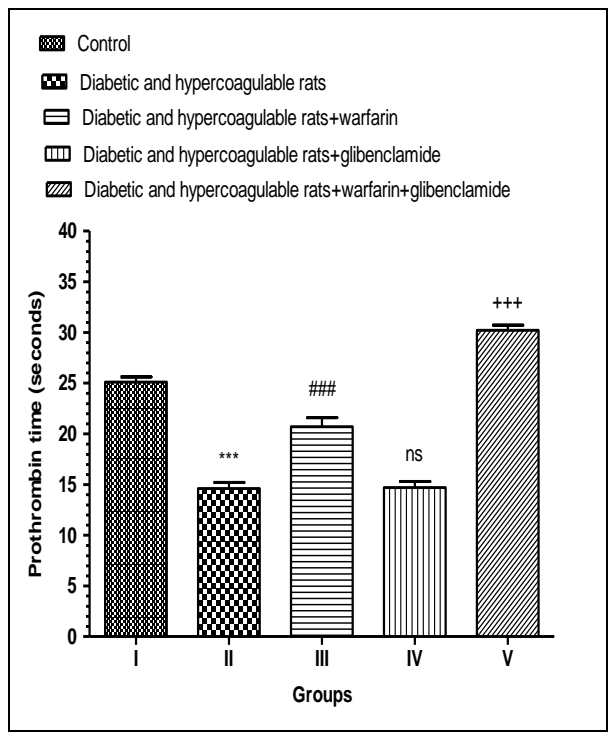

Fig. 1: Effect of warfarin $(0.07 \mathrm{mg} / \mathrm{kg})$, glibenclamide $(0.6 \mathrm{mg} / \mathrm{kg})$ and their combination on PT

Data represents the mean \pm SE of each group $(\mathrm{n}=10) . * * *$ : Highly significant in comparison with group I ( $<<$ 0.001). \#\#\#: Highly significant in comparison with group II ( $\mathrm{p}<$ 0.001). ns: Not significant in comparison with group II ( $p>0.05)$. +++: Highly significant in comparison with group III $(p<0.001)$ 


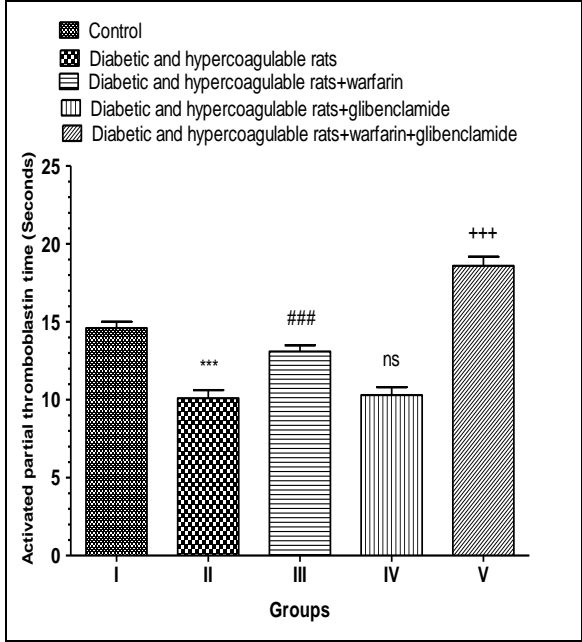

Fig. 2: Effect of warfarin $(0.07 \mathrm{mg} / \mathrm{kg})$, glibenclamide $(0.6 \mathrm{mg} / \mathrm{kg})$ and their combination on aPTT

Data represents the mean \pm SE of each group $(\mathrm{n}=10)$. ***: Highly significant in comparison with group I ( $p<0.001)$. \#\#\#: Highly significant in comparison with group II $(\mathrm{p}<0.001)$. ns: Not significant in comparison with group II ( $p>0.05)$. +++ : Highly significant in comparison with group III $(\mathrm{p}<0.001)$

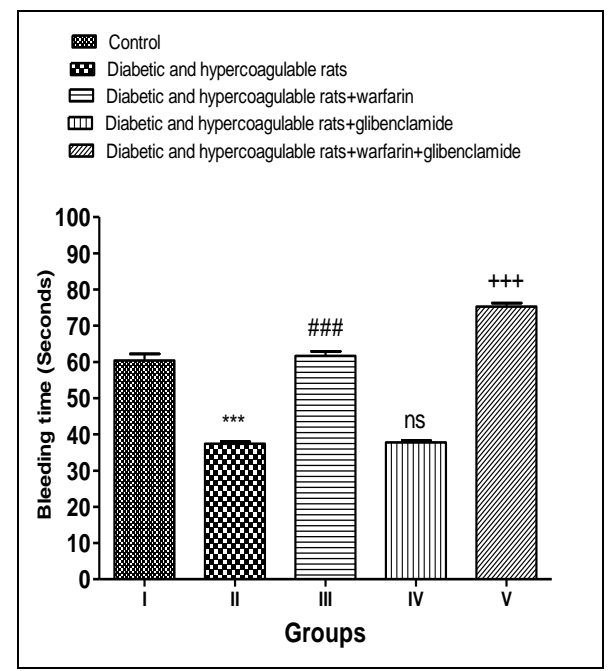

Fig. 3: Effect of warfarin $(0.07 \mathrm{mg} / \mathrm{kg})$, glibenclamide $(0.6 \mathrm{mg} / \mathrm{kg})$ and their combination on BT

Data represents the mean \pm SE of each group $(\mathrm{n}=10) . * * *$ : Highly significant in comparison with group I ( $<<$ 0.001). \#\#\#: Highly significant in comparison with group II $(\mathrm{p}<$ 0.001). ns: Not significant in comparison with group II ( $p>0.05)$. +++: Highly significant in comparison with group III $(\mathrm{p}<0.001)$

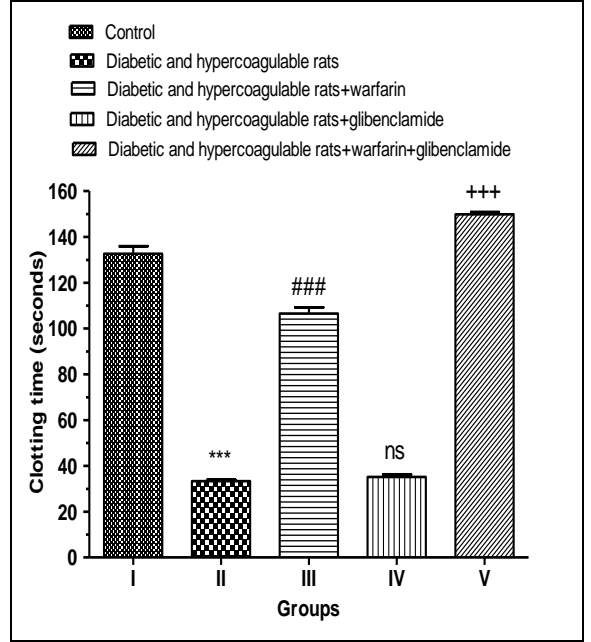

Fig. 4: Effect of warfarin $(0.07 \quad \mathrm{mg} / \mathrm{kg})$, glibenclamide $(0.6 \mathrm{mg} / \mathrm{kg})$ and their combination on $\mathrm{CT}$

Data represents the mean \pm SE of each group $(n=10)$. ***: Highly significant in comparison with group I ( $\mathrm{p}<0.001)$. \#\#\#: Highly significant in comparison with group II $(\mathrm{p}<0.001)$. ns: Not significant in comparison with group II ( $p>0.05)$. +++ : Highly significant in comparison with group III $(\mathrm{p}<0.001)$

In diabetic and hypercoagulable rats treated with glibenclamide $0.6 \mathrm{mg} / \mathrm{kg}$ orally for 5 consecutive days (group IV), PT, aPTT, BT and CT were not significantly changed in comparison with non-treated diabetic and hypercoagulable rats (group II). In diabetic and hypercoagulable rats treated with a combination of warfarin $0.07 \mathrm{mg} / \mathrm{kg}$ and glibenclamide $0.6 \mathrm{mg} / \mathrm{kg}$ orally for 5 consecutive days (group V), PT, aPTT, BT and CT were significantly $(\mathrm{p}<0.001)$ prolonged than diabetic and hypercoagulable rats treated with warfarin alone (group III).

\section{Effects on serum glucose level}

As shown in figure 5, serum glucose level was significantly $(\mathrm{p}<0.001)$ increased in diabetic and hypercoagulable rats (group II) in comparison with control rats (group I). In diabetic and hypercoagulable rats treated with warfarin $0.07 \mathrm{mg} / \mathrm{kg}$ orally for 5 consecutive days (group III), serum glucose level was not significantly changed in comparison with nontreated diabetic and hypercoagulable rats (group II).

In diabetic and hypercoagulable rats treated with glibenclamide $0.6 \mathrm{mg} / \mathrm{kg}$ orally for 5 consecutive days (group IV), serum glucose level was significantly $(\mathrm{p}<0.001)$ decreased in 
comparison with non-treated diabetic and hypercoagulable rats (group II). In diabetic and hypercoagulable rats treated with a combination of warfarin $0.07 \mathrm{mg} / \mathrm{kg}$ and glibenclamide $0.6 \mathrm{mg} / \mathrm{kg}$ orally for 5 consecutive days (group V), serum glucose level was significantly $(\mathrm{p}<0.001)$ decreased in comparison with diabetic and hypercoagulable rats treated with glibenclamide alone (group IV).

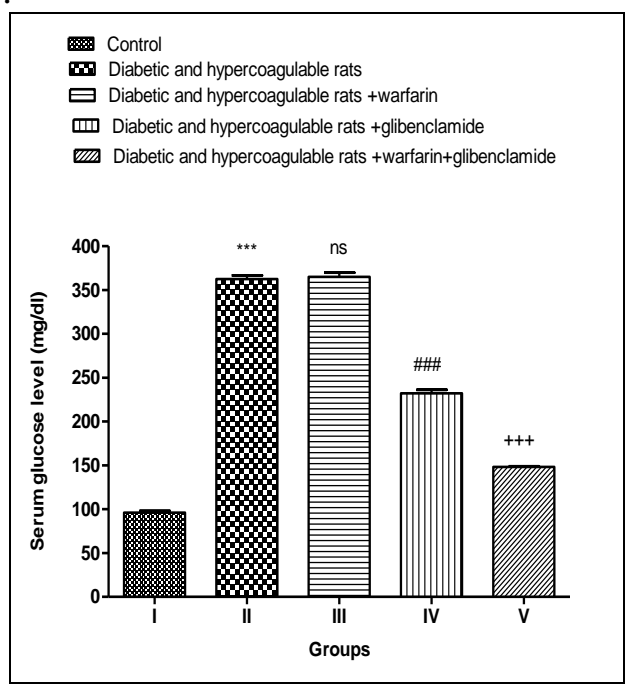

Fig. 5: Effect of warfarin $(0.07 \mathrm{mg} / \mathrm{kg})$, glibenclamide $(0.6 \mathrm{mg} / \mathrm{kg})$ and their combination on serum glucose level

Data represents the mean \pm SE of each group $(\mathrm{n}=10)$. ***: Highly significant in comparison with group I ( $\mathrm{p}<$ 0.001). \#\#\#: Highly significant in comparison with group II ( $\mathrm{p}<$ 0.001). ns: Not significant in comparison with group II ( $p>0.05)$. +++: Highly significant in comparison with group IV $(p<0.001)$

\section{Effects on HbA1c}

As shown in figure $6, \mathrm{HbA} 1 \mathrm{c}$ was significantly $(p<0.01)$ increased in diabetic and hypercoagulable rats (group II) in comparison with control rats (group I). In diabetic and hypercoagulable rats treated with warfarin $0.07 \mathrm{mg} / \mathrm{kg}$ orally for 5 consecutive days (group III), HbA1c was not significantly changed in comparison with non-treated diabetic and hypercoagulable rats (group II).

In diabetic and hypercoagulable rats treated with glibenclamide $0.6 \mathrm{mg} / \mathrm{kg}$ orally for 5 consecutive days (group IV), HbA1c was significantly $(\mathrm{p}<0.001)$ decreased in comparison with non-treated diabetic and hypercoagulable rats (group II). In diabetic and hypercoagulable rats treated with a combination of warfarin $0.07 \mathrm{mg} / \mathrm{kg}$ and glibenclamide $0.6 \mathrm{mg} / \mathrm{kg}$ orally for 5 consecutive days (group V), HbA1c was significantly $(\mathrm{p}<0.01)$ decreased in comparison with diabetic and hypercoagulable rats treated with glibenclamide alone (group IV).

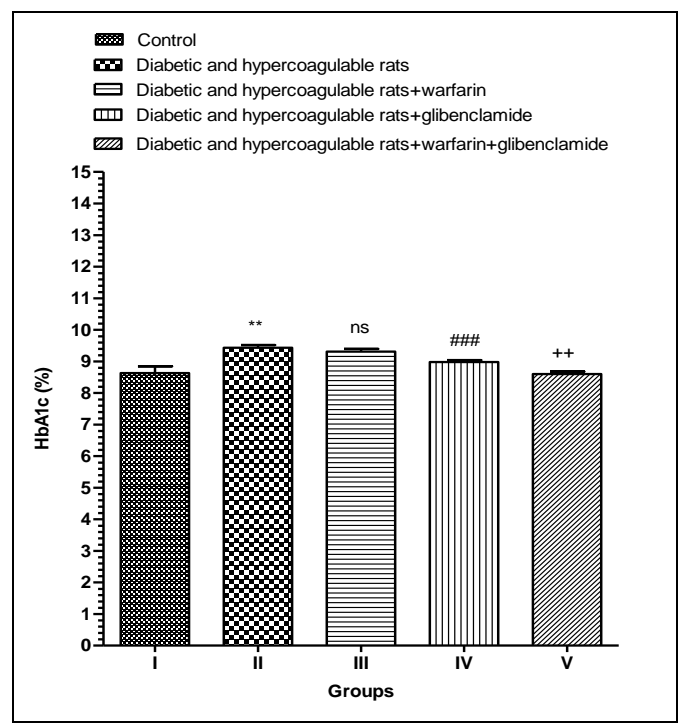

Fig. 6: Effect of warfarin $(0.07 \mathrm{mg} / \mathrm{kg})$, glibenclamide $(0.6 \mathrm{mg} / \mathrm{kg})$ and their combination on $\mathrm{HbA} 1 \mathrm{c}$

Data represents the mean \pm SE of each group $(\mathrm{n}=10){ }^{* *}$ : Highly significant in comparison with group I ( $\mathrm{p}<0.01)$. \#\#\#: Highly significant in comparison with group II ( $p<0.001)$. ns: Not significant in comparison with group II ( $p>$ $0.05)$. ++: Highly significant in comparison with group IV $(p<0.01)$.

\section{Discussion}

Patients with DM who are being treated with sulfonylureas, such as glibenclamide, may also be given warfarin, an oral anticoagulant medication, for the prevention and treatment of thromboembolic consequences of diabetes. In this case, there is a chance of a drug-drug interaction between warfarin and glibenclamide. A potential drug-drug interaction refers to the possibility of one drug to alter the pharmacodynamics and pharmacokinetics of another drug when they had given concurrently ${ }^{17}$.

In the present study, we had studied the effect of warfarin on the antidiabetic action of glibenclamide as well as the effect of glibenclamide on the anticoagulant action of warfarin in rats. Wafarin action was evaluated by measuring the PT, aPTT, CT and BT. while 
the antidiabetic action of glibenclamide was evaluated by measuring the serum glucose and HbA1c levels.

To evaluate the effects of warfarin and glibenclamide, an effective animal model of DM and hypercoagulable state that mimicked the clinical situation was required. According to Maniyar et $a l^{7}$, alloxan monohydrate 120 $\mathrm{mg} / \mathrm{kg}$ intraperitoneally as a single dosage caused experimental diabetes by damaging insulin-producing $\beta$ cells in the pancreas ${ }^{18}$.

In experimental animals, alloxan administration has been shown to cause pancreatic damage that is proportional to the dosage provided. The size of the lesion is also related to the amount of insulin in the pancreas. This might explain why, at low or medium doses, the medication does not cause absolute but inadequate insulin shortage in experimental animals ${ }^{19}$.

As a result of the partial death of pancreatic cells caused by the administration of a lower dose of alloxan monohydrate (120 $\mathrm{mg} / \mathrm{kg}$ ), type 2 diabetes is produced. As a result, these mice have surviving cells and insulin production is feasible, which is necessary for our animal diabetes model ${ }^{20}$. In compared to the control rats, the results indicated a substantial increase in blood glucose levels after one week of alloxan administration. These findings are consistent with other studies as ${ }^{7 \& 20}$.

According to Liu et al. ${ }^{9}$, an experimental hypercoagulable condition was established by administering $10.5 \mathrm{mg} / \mathrm{kg}$ ellagic acid intraperitoneally as a single dose $5 \mathrm{~min}$. before blood samples were collected. Ellagic acid is a polyphenol present in a variety of fruits ${ }^{9}$. This chemical has been linked to a variety of actions, including reducing inflammation in colon cancer cells ${ }^{21}$ to free radical scavenging ${ }^{22}$ and coagulation effects. The coagulation effects have been attributed to their effect on Hageman factor (factor XII) to trigger intrinsic coagulation system ${ }^{23}$.

The results of the current study showed that ellagic acid used dose had successfully induced a hypercoagulable state as a significant shortening of all coagulation parameters compared to the control rats. These results are consistent with Liu et al. ${ }^{9}$.

In the current investigation, warfarin was administered either alone or in combination with glibenlamide. The preliminary studies revealed that the submaximal dosage was 0.07 $\mathrm{mg} / \mathrm{kg}$ orally once day for 5 days. The findings revealed that warfarin at this dosage protected rats against the hypercoagulable impact of ellagic acid, with all coagulation parameters substantially extended in comparison to nontreated rats.

In comparison to the non-treated diabetic and hypercoagulable rats, this warfarin dosage had no effect on blood glucose levels or $\mathrm{HbA1c}$. This means that warfarin has no antidiabetic effect. Glibenclamide at $0.6 \mathrm{mg} / \mathrm{kg}$ was related with lower levels of glucose and HbA1c.

In comparison to the non-treated diabetic and hypercoagulable rats, glibenclamide at 0.6 $\mathrm{mg} / \mathrm{kg}$ showed no significant effect on coagulation indices. This means that glibenclamide has no anticoagulant effect, while diabetic and hypercoagulable rats treated with both warfarin and glibenclamide resulted in extended coagulation parameters.

In addition, blood glucose and $\mathrm{HbA} 1 \mathrm{c}$ levels were substantially lower in diabetic and hypercoagulable rats treated with glibenclamide alone. These data suggest that a drug-drug interaction occurred because glibenclamide improved warfarin's anticoagulant effect and warfarin enhanced glibenclamide's antidiabetic action when both medications were coadministered.

This interaction might be pharmacodynamic or pharmacokinetic. The potential of a pharmacodynamic interaction can be ruled out since warfarin has no antidiabetic effect and glibenclamide has no anticoagulant effect. As a result, it is most likely owing to pharmacokinetic interaction; plasma proteins and the hepatic CYP450 system are typical interaction sites ${ }^{24}$.

Glibenclamide can modify the anticoagulant action of warfarin through interference with CYP2C9-catalyzed Swarfarin 7-hydroxylation ${ }^{24 \& 25}$ and to lesser extent on CYP3A4 but it has no effect on CYP $1 \mathrm{~A} 2,2 \mathrm{C} 8,2 \mathrm{C} 19,2 \mathrm{E} 1$ and $2 \mathrm{D} 6^{26}$.

Protein-binding displacement might occur $^{24}$, since sulfonylureas and warfarin bind to plasma albumin, and each medication has been shown to be more than 99 percent bound. The medications may compete for binding sites on plasma albumin. The newly active unbound 
drug would be accessible for compensatory activation of metabolism, resulting in an increase in total drug clearance. As a result of this the unbound drug concentration returning to the predisplacement concentration ${ }^{27 \& 28}$.

Non-ionic force binds glibenclamide to human serum albumin. As a result, ionic medicines such as warfarin do not displace glibenclamide from albumin in the same way as the first generation sulfonylureas $\mathrm{do}^{29}$. According to these findings, protein binding displacement of warfarin is not a mechanism for medication interaction ${ }^{30}$.

Furthermore, because of decreased intrinsic clearance caused by metabolic restriction, the elimination of unbound warfarin would have been considerably delayed ${ }^{27}$. As a result, suppression of CYP2C9 appears to explain the observed effect of glibenclamide on warfarin's anticoagulant activity

Nam et al., ${ }^{31}$ discovered that when taken concurrently with a sulfonylurea in type 2 diabetes, warfarin was linked with an increased risk of severe hypoglycemia, which was more evident after extended concomitant treatment. As a result, patients are at a higher risk of hypoglycemia, which might lead to hospitalization or admission. These individuals should be continuously followed in order to decrease their risk of hypoglycemia and improve their quality of care ${ }^{31}$.

These findings might be explained by warfarin's suppression of osteocalcin carboxylation and a positive feedback loop. Osteocalcin is a protein that osteoblasts generate during bone growth. Its uncarboxylated form increases insulin secretion both directly on pancreatic islet cells and indirectly by increasing glucagon-like peptide1 production from the small intestine ${ }^{32}$.

Furthermore, uncarboxylated osteocalcin enhances insulin sensitivity ${ }^{33}$, with the combined impact predicted to lower blood glucose. The conversion of osteocalcin to its carboxylated form, which has no effect on glucose metabolism, requires vitamin $\mathrm{K}$ and is blocked by warfarin ${ }^{34}$.

In conclusion, our data suggest that doctors and patients should be aware of the increased risk of severe hypoglycemia associated with the use of warfarin during sulfonylurea treatment. When using warfarin and glibenclamide together, the doses of both drugs must be reduced to avoid severe drugdrug interactions such as bleeding and hypoglycemia. These patients must be monitored more closely to reduce their risk of hypoglycemia and improve their quality of care.

\section{Fund}

This research was partially supported by the Grants Office, Faculty of Medicine, Assiut University.

\section{Acknowledgment}

Authors would like to acknowledge Dr. Hanan Sayed Mohamed Farghly, Professor of Pharmacology, Faculty of Medicine, Assiut University for her assistance in writing and revising this manuscript.

\section{REFERENCES}

1. S. Pouya, I. Petersohn, P. Salpea, B. Malanda, S. Karuranga, N. Unwin, S. Colagiuri, L. Guariguata, A. A. Motala, K. Ogurtsova , J. E. Shaw, D. Bright and R. Williams, "IDF Diabetes Atlas Committee. Global and regional diabetes prevalence estimates for 2019 and projections for 2030 and 2045: Results from the International Diabetes Federation Diabetes Atlas, $9^{\text {th }}$ edition, Diabetes Res Clin Pract, 157, 107843 (2019).

2. S. Rahman, M. d. A. A. Majumder, R. Kabir, M. Haque, S. Gupta, S. Mohammad, Y. Arafat, N. Ojeh and P. Dalvi, "Cardiovascular Disease and Diabetes: Two Sides of the Same Coin!" In: Recent Trends in Cardiovascular Risks, London, UK. (2017).

3. M. J. S. Frederico, A. J. G. Castro, D. Menegaz, C. B. Murat, C. P. Mendes, A. Mascarello, R. J. Nunes and F. R. M. B. Silva "Mechanism of Action of Novel Glibenclamide Derivatives on Potassium and Calcium Channels for Insulin Secretion" Curr Drug Targets, 18, 641-650 (2017).

4. J. Ansell, J. Hirsh, E. Hylek, A. Jacobson, M. Crowther and G. Palareti, "Pharmacology and management of the vitamin $\mathrm{K}$ antagonists.: American College of Chest Physicians Evidence- 
Based Clinical Practice Guidelines", $8^{\text {th }}$ edition, Chest, 133, 160-198 (2008).

5. D. S. H. Bell and E. Goncalves, "Should we still be utilizing warfarin in the type 2 diabetic patient?" Diabetes Obes and Metab, 20, 2327-2329 (2018).

6. S. Namazi and G. Rozitalab, "Case Presentation of a 45 Years Old Woman with Hypoglycemiaand Bleeding", Iran J Pharm Sci, 1, 183-188 (2005).

7. Y. Maniyar and P. Bhixavatimath, "Antihyperglycemic and hypolipidemic activities of aqueous extract of Carica papaya Linn. Leaves in alloxan-induced diabetic rats", J Ayurveda Integr Med, 3, 70-74 (2012).

8. R. Ananthan, M. Latha, K.M. Ramkumar, L. Pari, C. Baskar and V. B. Narmatha, "Modulatory effects of Gymnema montanum leaf extract on alloxan-induced oxidative stress in Wistar rats", Nutrition, 20:280-285 (2003).

9. N. Liu, J. Liu and Q. Zhang, "Ellagic Acid-induced Hypercoagulable State in Animals: A potentially useful animal hypercoagulable model for evaluation of anticoagulants", Chin Med Sci J, 25, 237-242 (2010).

10. I. Y. Zaghloul, Z. H. Aly and M. A.Radwan, "Effect of ciprofloxacin on the hypoprothrombinemic activity of warfarin in rats", Int $\boldsymbol{J}$ Pharm, 131(2), 131-136 (1996).

11. O. O. Erejuwa, S. A. Sulaiman, M. S.Wahab, S. K.Salam, M.S. Salleh and S. Gurtu, "Comparison of antioxidant effects of honey, glibenclamide, metformin, and their combinations in the kidneys of streptozotocin-induced diabetic rats", Int J Mol Sci, 12, 829843 (2011).

12. K. Balamurugan, A. Nishanthini and R. V. Mohan, "Antidiabetic and antihyperlipidaemic activity of ethanol extract of Melastoma malabathricum Linn. leaf in alloxan induced diabetic rats" Asian Pac J Trop Biomed, 4, 442448 (2014).

13. S. Parasuraman, R. Raveendran and R. Kesavan, "Blood sample collection in small laboratory animals", $\boldsymbol{J}$
Pharmacol Pharmacother, 1(2), 87-93 (2010).

14. C. Zoga, M. Noris, D. Corna, G. Vigano, N. Perico, G. de Gaetano and G. Remuzzi, "L-arginine, the precursor of nitric oxide, abolishes the effect of estrogens on bleeding time in experimental uremia", Lab Invest., 65, 479-483 (1991).

15. A.C. Ivy, D. Nelson and G. Bucher, "The standardization of certain factors in the cutaneous "venostasis" bleeding time technique" J Lab Clin Med, 26, 1812-1822 (1941).

16. J.O. Ibu and K.O. Adeniyi, "A Manual of Practical Physiology" (1st edition). Jos University Press Ltd, Jos, Nigeria. 17-32 (1989).

17. S. Hennessy, C. E. Leonard, J. J. Gagne, J. H. Flory, X. Han, C. M. Brensinger and W. B. Bilker, "Pharmacoepidemiologic methods for studying the health effects of drug-drug interactions", Clin Pharmacol Therap, 99 (1), 92-100 (2016).

18. T. Szkudelski, "The mechanism of alloxan and streptozotocin action B cells of the rat pancreas", Physiol Res, 50, 536-546 (2001).

19. M. J. Ayber, A. N. Riera, A. Grau and S. S. Sanchhez, "Hypoglycemic effect of Smallanthus soncitolius water extract of leaves in normal and diabetic rats", $\boldsymbol{J}$ Ethnopharmacol, 74, 125-132 (2001).

20. M. Y. Gwarzo, J. H. Ahmadu, M. B. Ahmad and A. U. A. Dikko, "Serum Glucose and Malondialdehyde Levels in Alloxan Induced Diabetic Rats Supplemented with Methanolic Extract of Tacazzea Apiculata", Inter J biomed Sci, 10, 236-42 (2014).

21. L.S. Adams, N. P. Seeram, B.B. Aggarwal, Y. Takada, D. Sand and D. Heber "Pomegranate juice, total pomegranate ellagitannins, and punicalagin suppress inflammatory cell signaling in colon cancer cells", $\boldsymbol{J}$ Agric Food Chem, 54,980-985 (2006).

22. N. Rangkadilok, S. Sitthimonchai, L. Worasuttayangkurn, C. Mahidol, M. Ruchirawat and J. Satayavivad "Evaluation of free radical scavenging and antityrosinase activities of 
standardized longan fruit extract", Food Chem Toxicol, 45, 328-336 (2007).

23. E. Stavrou, H. Alvin and A. H. Schmaier, "Factor XII: What does it contribute to our understanding of the physiology and pathophysiology of hemostasis \& thrombosis", Thrombosis Res, 125, 210-21 (2010).

24. J. R. Horn and P. D. Hansten, "Do warfarin and sulfonylureas interact with each other" Autoimmune Disorders, 82 (2016)

25. J. A. Romley, C. Gong, A. B. Jena, D. P. Goldman, B. Williams and A. Peters "Association between use of warfarin with common sulfonylureas and serious hypoglycemic events: retrospective cohort analysis", BMJ, 351, h6223 (2015).

26. K. A. Kim and J. Y. "Park Inhibitory effect of glyburide on human cytochrome p450 isoforms in human liver microsomes", Drug Metab Dispos, 31, 1090-1092 (2003).

27. M. Gibaldi and J. R. Koup, "Pharmacokintic concepts of drug binding, apparent volume of distribution and clearance" Europ $J$ Clin Pharmacol, 20, 299-305 (1981).

28. P. D. Hansten and J. R. Horn, "Principles and mechanisms. In: Drug Interactions Analysis and Management", P. A. Philadelphia and W. Kluwer, Health, 2014, PM9-PM13 (2014).
29. A. Plum, L. K. Muller and J. A. Jansen, "The effect of selected drugs on the in vitro protein binding of repaglinde in human plasma", Methods Find Exp Clin Pharmacol, 22, 139-143 (2000).

30. C.D. Sanads, E.S. Chan and T.E. Welty, "Revisiting the significance of warfarin protein binding displacement interactions", Ann Pharmacother., 36, 1640-1644 (2002).

31. Y. H. Nam, C. M. Brensinger, W. B. Bilker, C. E. Leonard, X. Han and S. Hennessy, "Serious hypoglycemia and use of warfarin in combination with sulfonylureas or metformin", Clin Pharmacol Therap, 105, 210-218 (2019).

32. A. Mizokami, T. Kawakubo-Yasukochi and M. Hirata, "Osteocalcin and its endocrine functions" Biochem Pharmacol, 132, 1-8 (2017).

33. K. Fulzele, R.C. Riddle, D. J. Dgirolamo, X. Cao, C. Wan, D Chen, M-C. Faugere, S. Aja, M. A. Hussain, J. C. Bruning and T. L. Clemens, "Insulin receptor signaling in osteoblasts regulates postnatal bone acquisition and body composition. Cell, 142, 309-319 (2010).

34. M. Ferron, J. Wei, T. Yoshizawa, P. Ducy and G. Karsenty, "An ELISAbased method to quantify osteocalcin carboxylation in mice", Biochem Biophys Res, 397, 691-696 (2010). 


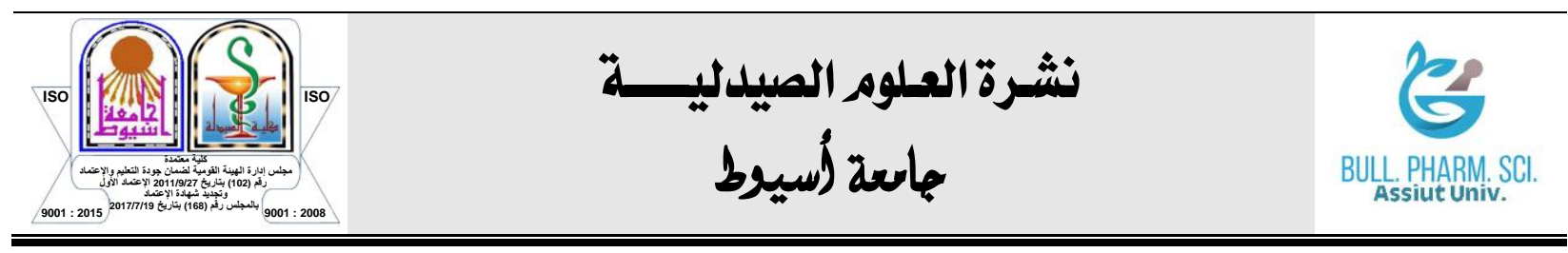

\section{التفاعل الاوائي المحتمل بين الوارفارين والجليبينكلاميد في نموذج الجرذان

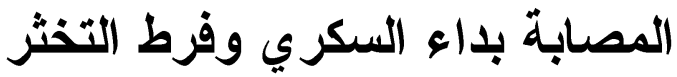 \\ صفاء يوسف سالم - محمد سيد مله - محمود حمدي عبد الرحيم \\ قسم علم الادوية (الفارماكولوجي) ، كلية الطب ، جامعة اسيوط}

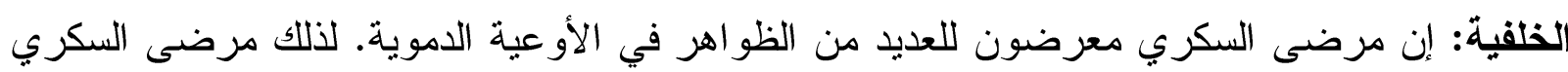

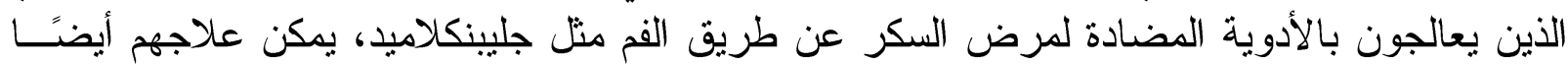

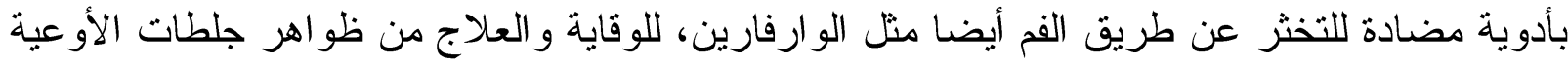
الاموية أو (التخثر العصيدي).

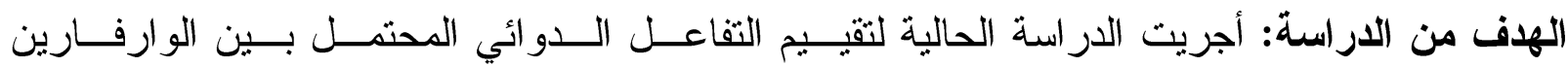

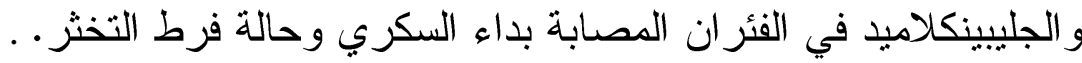

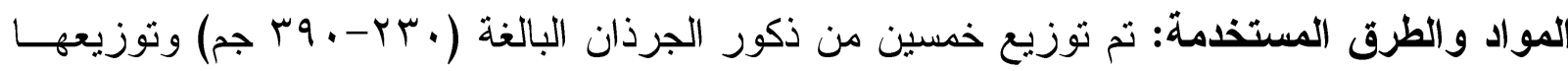

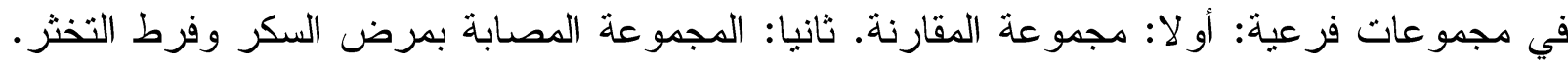

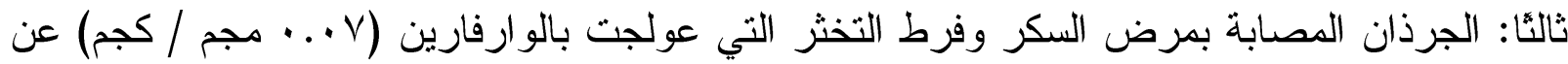

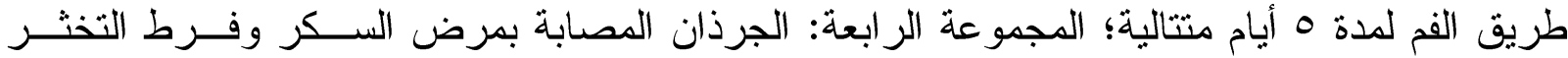

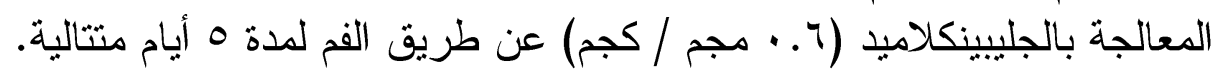

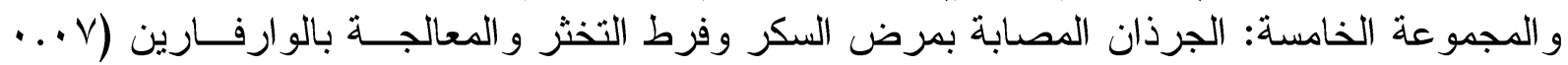

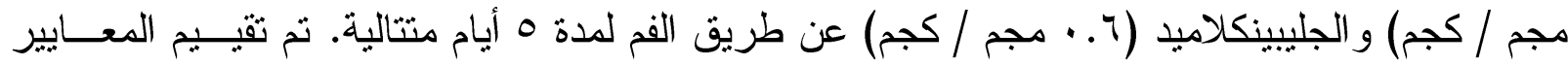

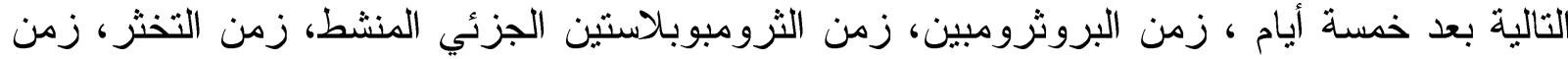

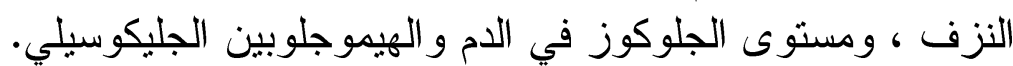

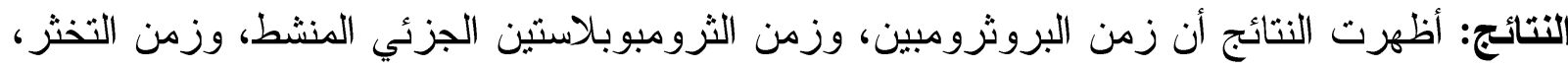

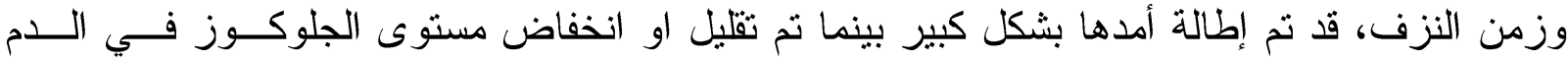

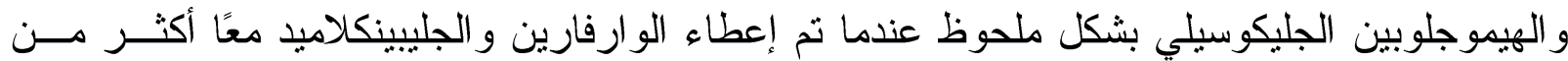
إعطاء كل منهما بمفرده.

الاستتناج: حدوث تفاعل بين الأدوية عندما تم تتاول الو ارفارين و الجليبينكلاميد معا. 